\section{What is already known on this topic}

Many clinicians and researchers conduct Medline searches independently but lack skills to do this well

A barrier to searching for evidence in Medline is the difficulty selecting an optimal strategy to search for information

\section{What this study adds}

Special Medline search strategies were developed and tested that retrieve $99 \%$ of scientifically sound therapy articles

Clinicians can use the most specific search when looking for a few sound articles on a topic

Researchers can use the most sensitive search when carrying out a comprehensive search for trials for their systematic reviews

larger 2000 database. ${ }^{8}$ The precision of searches, however, depends on the concentration of relevant articles in the database. We selected clinical journals to calibrate the search strategies, but Medline contains many non-clinical journals. Thus, the concentration of high quality treatment studies will be less in the full Medline database, and the precision of searches will be less accordingly.

Searchers who want retrieval with little nonrelevant material can choose strategies with high specificity. For those interested in comprehensive retrievals, strategies with higher sensitivity will be more appropriate. The most effective way to harness these strategies is to have them embedded within searching systems. The most sensitive and most specific search strategies reported here have been implemented in the Clinical Queries search screen (www.ncbi.nlm. nih.gov:80/entrez/query/static/clinical.html) and by Ovid Technologies (www.ovid.com), and the optimal strategy has been added to Skolar (www.skolar.com).

The Hedges Team includes Angela Eady, Brian Haynes, Susan Marks, Ann McKibbon, Doug Morgan, Cindy Walker-Dilks, Stephen Walter, Stephen Werre, Nancy Wilczynski, and Sharon Wong, all at McMaster University Faculty of Health Sciences. Contributors: See bmj.com

Funding: National Institutes of Health (grant RO1 LM06866-01). Competing interests: None declared.

Ethical approval: Not required.

1 Robinson KA, Dickersin K. Development of a highly sensitive search strategy for the retrieval of reports of controlled trials using PubMed. Int JEpidemiol 2002;31:150-3.

2 Nwosu CR, Khan KS, Chien PF. A two-term Medline search strategy for identifying randomized trials in obstetrics and gynecology. Obstet Gynecol 1998.91:618-29

3 Marson AG, Chadwick DW. How easy are randomized controlled trials in epilepsy to find on Medline? The sensitivity and precision of two Medline searches. Epilepsia 1996;37:377-80

4 Adams CE, Power A, Frederick K, LeFebvre C. An investigation of the adequacy of Medline searches for randomized controlled trials (RCTs) of the effects of mental health care. Psychol Med 1994;24:741-8.

5 Dumbrigue HB, Esquivel JF, Jones JS. Assessment of Medline search strategies for randomized controlled trials in prosthodontics. $J$ Prosthodont 2000:9:8-13.

6 Jadad AR, McQuay HJ. A high-yield strategy to identify randomized controlled trials for systematic reviews. Online J Curr Clin Trials 1993:No 33

7 Haynes RB, Wilczynski N, McKibbon KA, Walker CJ, Sinclair JC Developing optimal search strategies for detecting clinical sound studies in Medline.J Am Med Inform Assoc 1994;1:447-58.

8 Wilczynski NL, Haynes RB. Robustness of empirical search strategies for clinical content in Medline. Proc AMIA Symp 2002;:904-8.

9 Haynes RB, Wilczynski NC for the Hedges Team. Optimal search strategies for retrieving scientifically strong studies of diagnosis from Medline. BMJ 2004;328:1040-2.

10 Montori VM, Wilczynski NL, Morgan D, Haynes RB for the Hedges Team. Optimal search strategies for retrieving systematic reviews from Medline: an analytical survey $B M J$ 2005:330:68-73.

11 University of Rochester Medical Center. Edward G. Miner Library. Eniversity of Rochester Medical Center. Edward G. Miner Library. Miner/links/eBMlinks.html\#TOOLS (accessed 22 May 2003).

12 Julien JP, Bijker N, Fentiman IS, Peterse JL, Delledonne V, Rouanet P, et al Radiotherapy in breast-conserving treatment for ductal carcinoma in situ: first results of the EORTC randomised phase III trial 10853. EORTC Breast Cancer Cooperative Group and EORTC Radiotherapy Group. Lancet 2000;355:528-33.

(Accepted 31 March 2005)

doi $10.1136 /$ bmj. $38446.498542 .8 \mathrm{~F}$

\title{
Medical dress code
}

We sometimes have to help our students to understand that what they wear influences the way they are seen by patients and colleagues, so affecting their ability to do the job. We may find that we are hesitant to point this out to them nowadays (even when faced, for example, with a bare midriff) for fear of being thought a fuddy-duddy. It is sometimes said that this laxity of dress is a modern phenomenon. I'm not so sure.

I recall going for my anatomy viva in June 1964, at the end of my first year at Cambridge. I had heard that one was expected to wear a gown on these occasions, so I put on my gown over my usual uniform. The examiner was a Dr Bull, an elderly (or so he seemed to me) anatomy lecturer of rather Victorian appearance, with mutton chop whiskers and beetling eyebrows. We went through the viva. The only question I can still remember was being asked to identify a beautiful dissection of the superior and inferior hemiazygos veins. This was so much in contrast with my own sad efforts in the dissecting room that I could not help expressing my admiration. To be honest, I think I might also have been trying to flatter Dr Bull, in the hope that he had done the dissection himself. At any rate, when the time was up Dr Bull drew himself up, looked at me, and said, "Well, Rushton, you've passed."

"Thank you, Sir."

"But in future please remember, when you come to examinations here, we expect you to wear a tie." He looked at my bare neck.

"A jacket." He looked at my sweater.

"Trousers." He looked at my jeans.

"And shoes." He looked at my sandals.

"Yes, Sir." Mortified, I fled.

The rebuke had been given gently, but, as you see, I do remember it.

David N Rushton consultant in rehabilitation, Frank Cooksey Rehabilitation Unit, King's College Hospital, London (david.rushton@kingsch.nhs.uk) 